\title{
INSIGHT INTO THE EFFECTS OF BAY-SUBSTITUENTS ON STABLE PERYLENE DIIMIDE RADICAL ANION SALTS
}

\author{
Yuzhen Zhao ${ }^{\mathrm{a}, *, \odot}$, Yang Zhao $^{\mathrm{a}}$, Zhun Guo $^{\mathrm{a}}$, Xiaoxi Kang ${ }^{\mathrm{a}}$, Zongcheng Miao ${ }^{\mathrm{a}}$ and Haiquan Zhang ${ }^{\mathrm{b}}$ \\ ${ }^{a}$ School of Sciences, Xijing University, Xi' an 710123, China \\ ${ }^{\mathrm{b}} \mathrm{School}$ of materials science and Engineering, Yanshan University, Qinhuangdao 066004, China
}

Recebido em 16/03/2020; aceito em 05/05/2020; publicado na web em 30/06/2020

\begin{abstract}
In previous work, the facile method to prepare perylene diimide radical anion salt by alkali treatment was reported. However, the effects of structure on synthetic process of perylene diimide radical anion salt, and the difference of response to $\mathrm{Cu}^{2+}$ are not thoroughly understood. In this work, two bay-substituted perylene diimide derivatives radical anion salts have been synthesized and characterized in order to study the influence of the bay-substituted groups on the formation condition of the corresponding radical anion salt, and the sensitivity to $\mathrm{Cu}^{2+}$. The result indicates that the perylene diimide with electron-donating groups (-O-Ph) at bay position was much easier to get the air-stable radical anion salts and had higher sensitivity to $\mathrm{Cu}^{2+}$ compared to the perylene diimide with electron-withdrawing groups (-Br) at bay position.
\end{abstract}

Keywords: perylene diimide radical anion salt; bay-substituted groups; reduction potential; synthesis condition; sensitive.

\section{INTRODUCTION}

Perylene diimide derivatives (PDIs) are promising and versatile electron-poor conjugated aromatic candidates for organic photoelectronic applications such as transistors, solar cells due to their commercial availability, low cost, and significant performance. ${ }^{1,2}$ The success of PDIs in these applications is fundamentally attributed to the high electron affinity and the ease of reduction into rather stable and delocalized radical anions that are the common features of electron-deficient aromatic diimides. ${ }^{3,4}$ PDIs radical anions is getting more and more attentions due to their applications in sensor, photo thermal conversion and reduction of aryl halides etc. ${ }^{5-7}$ The reduction of electrochemistry and the chemical reductant $\left(\mathrm{Na}_{2} \mathrm{~S}\right.$, $\mathrm{Na}_{2} \mathrm{~S}_{2} \mathrm{O}_{4}, \mathrm{NH}_{2} \mathrm{NH}_{2}$, etc ) are the typical method to prepare perylene diimide radical anion. ${ }^{8-10}$ It is well know that the perylene diimide radical anion as an independent species in the air was not obtained by electrochemistry method due to the reducibility of radical anion. ${ }^{11}$ The stable perylene diimide anion in deoxygenated aqueous solution has been developed by the reduction of the chemical reductants in recent year. For example, Rybtchinski and co-workers reported that a coreunsubstituted PDI containing polyethylene glycol chains at the imide positions can be reduced with sodium dithionite $\left(\mathrm{Na}_{2} \mathrm{~S}_{2} \mathrm{O}_{4}\right)$ in water to its dianion, this species was stable for months in deoxygenated aqueous solution owing to the delocalized aromatic character. ${ }^{10}$ Furthermore, Brochsztain et al. investigated the aggregation behavior of a PDIs dianion generated by $\mathrm{Na}_{2} \mathrm{~S}_{2} \mathrm{O}_{4}$ titration in water-ethanol mixtures. ${ }^{12}$ Michael R. W first reported radical anions of the trifluoromethylated perylene diimide with cobaltocene as reducing agent in DMF. ${ }^{13}$ Unfortunately, those perylene diimide anions are unstable in the air. Würthner, F. and co-workers reported the first example of an isolable, ambient stable perylene diimide (PDI) dianion by catalytic reduction $\left(\mathrm{Pd} / \mathrm{C}, \mathrm{H}_{2}\right)$ for a highly electron-deficient PDI derivative. ${ }^{14}$ However, their methods tend to require the severe preparation conditions (such as: composite catalytic system $\left(\mathrm{Pd} / \mathrm{C}-\mathrm{H}_{2}\right)$, nitrogen atmosphere, etc.) and complex molecular structure, which limits the application of perylene diimide anion. Recently, the preparation method of perylene diimide radical anion salt has been obtained by alkali

*e-mail: zyz19870226@163.com treatment in DMF and air atmosphere in our research group. ${ }^{15}$ The structure characterization, the effect of solvent on synthetic reaction, and the sensitive to oxidants-acid $\mathrm{H}^{+}$and oxidization metal ions for $N, N^{\prime}$-diethylhexyl-1,7-di(pentafluoro-phenoxyl) perylene diimide radical anion have been widely discussed in our study. However, understanding the effects of bay-substituents on synthesis process of perylene diimide radical anion salt, and the difference of response to $\mathrm{Cu}^{2+}, \mathrm{Hg}^{2+}$ ion has always been a challenging topic.

In this paper, we reported the synthesis process and properties of two PDIs radical anion salt with electron-withdrawing groups and electron-donating groups ( Synthetic route and structure see Scheme 1).

\section{EXPERIMENTAL}

\section{Material}

Materials: All reactions were carried out under an argon atmosphere. All reagents from commercial sources were used without further purification unless otherwise stated. Dimethyl Formamide (DMF) was fractionally distilled under reduced pressure.

\section{Characterization}

Infrared measurement with the $\mathrm{KBr}$ pellet technique was performed within the $400-4000 \mathrm{~cm}^{-1}$ on a Perkin Elemer SP100 Fourier transform infrared spectrometer. UV-Vis spectra were measured by Perkin Elemer Lambda 35. Cyclic voltammetry measurements were performed in solution, under argon atmosphere with a computer controlled CHI600E electrochemical workstation in a three electrode single- compartment cell using platinum electrodes and $\mathrm{Ag} / \mathrm{AgCl}$ electrode as reference electrode, with $\mathrm{Fc} / \mathrm{Fc} *$ redox couple as internal standard, with a tetrabutyl-ammonium hexafluorophosphate $\left(\mathrm{Bu}_{4} \mathrm{NPF}_{6}\right)$ solution $\left(0.1 \mathrm{~mol} \mathrm{~L}^{-1}\right)$ in DMF at a scan rate of $0.1 \mathrm{~V} \mathrm{~s}^{-1}$.

\section{Synthesis of materials}

N,N'-diethylhexyl-1,7-di (p-tertbutylphenoxyl) perylene diimide 
(DBOPDI) and N,N'-diethylhexyl-1,7-dibromo- perylene diimide (DBrPDI) were synthesized in our group. ${ }^{16}$

\section{DBOPDI radical anion salt}

A mixture of $N, N^{\prime}$-diethylhexyl-1,7-di (p-tertbutylphenoxyl) perylene diimide (DBOPDI) (0.46 g, $0.5 \mathrm{mmol}, 1$ eq.) and DMF $(17 \mathrm{~mL})$ first undergone stirring on a magnetic stirrer thermostat for $10 \mathrm{~min}$ at room temperature. Then add potassium carbonate ( 2 eq.) as a catalyst and the temperature was adjusted to $85{ }^{\circ} \mathrm{C}$ and kept for $24 \mathrm{~h}$. After the reaction, the solvent was removed by rotary evaporation. The solid residue was thoroughly washed with enough water and then was vacuum-dried at $80{ }^{\circ} \mathrm{C}$ for $24 \mathrm{~h}$. Then, the crude product was dissolved in eluent [V (petroleum ether): $\mathrm{V}(\mathrm{THF})=3: 1$ ] and purified by column chromatography on silica 200-300 to afford the DBOPDI radical anion salt $(0.224 \mathrm{~g}$, 0.24 mmol, yield: $48.7 \%$ ). FT-IR(KBr), v: $2960 \mathrm{~cm}^{-1}, 2933 \mathrm{~cm}^{-1}$, $2871 \mathrm{~cm}^{-1}, 1730 \mathrm{~cm}^{-1}, 1697 \mathrm{~cm}^{-1}, 1656 \mathrm{~cm}^{-1}, 1595 \mathrm{~cm}^{-1}, 1506 \mathrm{~cm}^{-1}$, $1461 \mathrm{~cm}^{-1}, 1284 \mathrm{~cm}^{-1}, 1122 \mathrm{~cm}^{-1}, 1074 \mathrm{~cm}^{-1}$. UV-vis: $\lambda_{\max }: 700 \mathrm{~nm}$ and $757 \mathrm{~nm}$. EPR: $338.22 \mathrm{G}$ and $338.85 \mathrm{G}$.

\section{DBrPDI radical anion salt}

A mixture of N,N'-diethylhexyl-1,7-dibromo- perylene diimide (DBrPDI) (0.385 g, $0.50 \mathrm{mmol}, 1$ eq.) and DMF (17 mL) first undergone stirring on a magnetic stirrer thermostat for $10 \mathrm{~min}$ at room temperature. Then add potassium carbonate ( 2 eq.) as a catalyst and the temperature was adjusted to $85^{\circ} \mathrm{C}$ and kept for $24 \mathrm{~h}$. After the reaction, the solvent was removed by rotary evaporation. The solid residue was thoroughly washed with enough water and then was vacuum-dried at $80^{\circ} \mathrm{C}$ for $24 \mathrm{~h}$. Then, the crude product was dissolved in eluent [V (petroleum ether): $\mathrm{V}(\mathrm{THF})=3: 1]$ and purified by column chromatography on silica 200-300 to afford the DFPDI radical anion salt (0.488 g, $0.302 \mathrm{mmol}$, yield: $60.5 \%)$. FTIR(KBr), v: $2956 \mathrm{~cm}^{-1}, 2927 \mathrm{~cm}^{-1}, 2858 \mathrm{~cm}^{-1}, 1720 \mathrm{~cm}^{-1}, 1697 \mathrm{~cm}^{-1}$, $1656 \mathrm{~cm}^{-1}, 1585 \mathrm{~cm}^{-1}, 1460 \mathrm{~cm}^{-1}, 1434 \mathrm{~cm}^{-1}, 1402 \mathrm{~cm}^{-1}, 1332 \mathrm{~cm}^{-1}$, $1244 \mathrm{~cm}^{-1}, 1186 \mathrm{~cm}^{-1}$. UV-vis: $\lambda_{\max }: 705 \mathrm{~nm}$ and $766 \mathrm{~nm}$. EPR: $339.12 \mathrm{G}$ and $339.71 \mathrm{G}$.

\section{RESULTS AND DISCUSSION}

\section{Synthesis and Structure characterization}

DBOPDI and DBrPDI have been synthesized according to relevant literature. The chemical structure of DBOPDI and DBrPDI has been confirmed by ${ }^{1} \mathrm{H}$ NMR, ${ }^{13} \mathrm{C}$ NMR spectroscopy and FT-IR spectrophotometry in our research. Synthetic route for DBOPDI ${ }^{+}{ }^{+}$ and $\mathrm{DBrPDI}^{-} \mathrm{K}^{+}$are showed in Scheme 1.

FT-IR spectra of the DBOPDI and DBrPDI radical anion was showed in supporting information (Figure $1 \mathrm{~S}$ and Figure $2 \mathrm{~S}$ ). In contrast with its patent, both the $\mathrm{N}-\mathrm{C}=\mathrm{O}$ and $\mathrm{C}=\mathrm{C}$ stretch bands somewhat shifted from 1704 and $1667 \mathrm{~cm}^{-1}(\mathrm{~N}-\mathrm{C}=\mathrm{O})$ to 1696 and $1656 \mathrm{~cm}^{-1}(\mathrm{~N}-\mathrm{C}=\mathrm{O})$ and from 1600 and $1518 \mathrm{~cm}^{-1}(\mathrm{C}=\mathrm{C})$ to 1594 and $1515 \mathrm{~cm}^{-1}(\mathrm{C}=\mathrm{C})$. The characteristic shift to lower wave-number belongs to the additional amount of electron density that was localized in the $\mathrm{C}=\mathrm{O} \pi^{*}$ orbital.

Due to the paramagnetic PDIs radical anion salt, to get signal from ${ }^{1} \mathrm{H}$ and ${ }^{13} \mathrm{C}$ NMR spectroscopy is difficult. However, a favorable evidence to confirm presence of PDIs radical anion salt came from the UV-vis absorption spectra (Figure 1a) and EPR spectroscopy (Figure 1b). The characteristic peak (0-0 transition) of neutral perylene diimide appeared at $525 \mathrm{~nm}$ and $545 \mathrm{~nm}$ for DBrPDI and DBOPDI, respectively. In contrast, new characteristic peaks were observed at $768 \mathrm{~nm}$ ture of Pand $759 \mathrm{~nm}$ for DBrPDI ${ }^{-} \mathrm{k}^{+}$ and DBOPDI $\mathrm{k}^{+}$, respectively. ${ }^{17}$ Furthermore, maximal absorption bond (0-0 transition) of neutral perylene diimide disappeared in the absorption spectra for DBrPDI ${ }^{*} \mathrm{k}+$ and DBOPDI ${ }^{*} \mathrm{k}+$, which was also a favorable evidence for the formation of PDIs radical anion salt.

EPR spectroscopy obtained at room temperature at X-band $(9.5 \mathrm{GHz})$ with $0.02 \mathrm{mT}$ field modulation was further used to obtain information on the spin density distribution within the anion radicals of PDIs (Figure 1b). In agreement with the values reported for paramagnetic PDI radical anion, the strong EPR signals were observed expounding the presence of paramagnetic radical anion..$^{9,15}$ The different magnetic field also suggested the strong interactions between the unpaired spin and the electron-withdrawing groups.
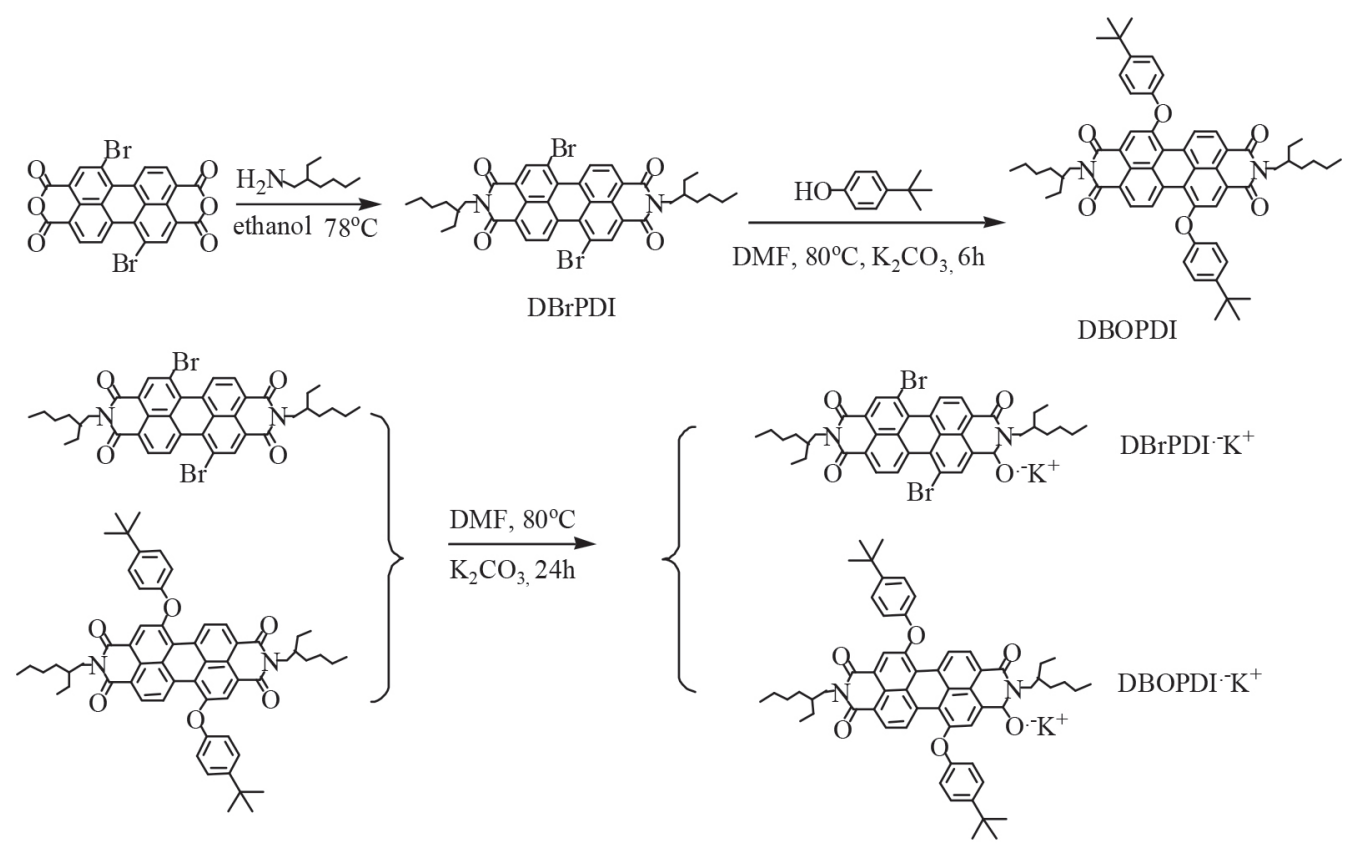

Scheme 1. Synthetic route and structure of PDIs radical anion salt 

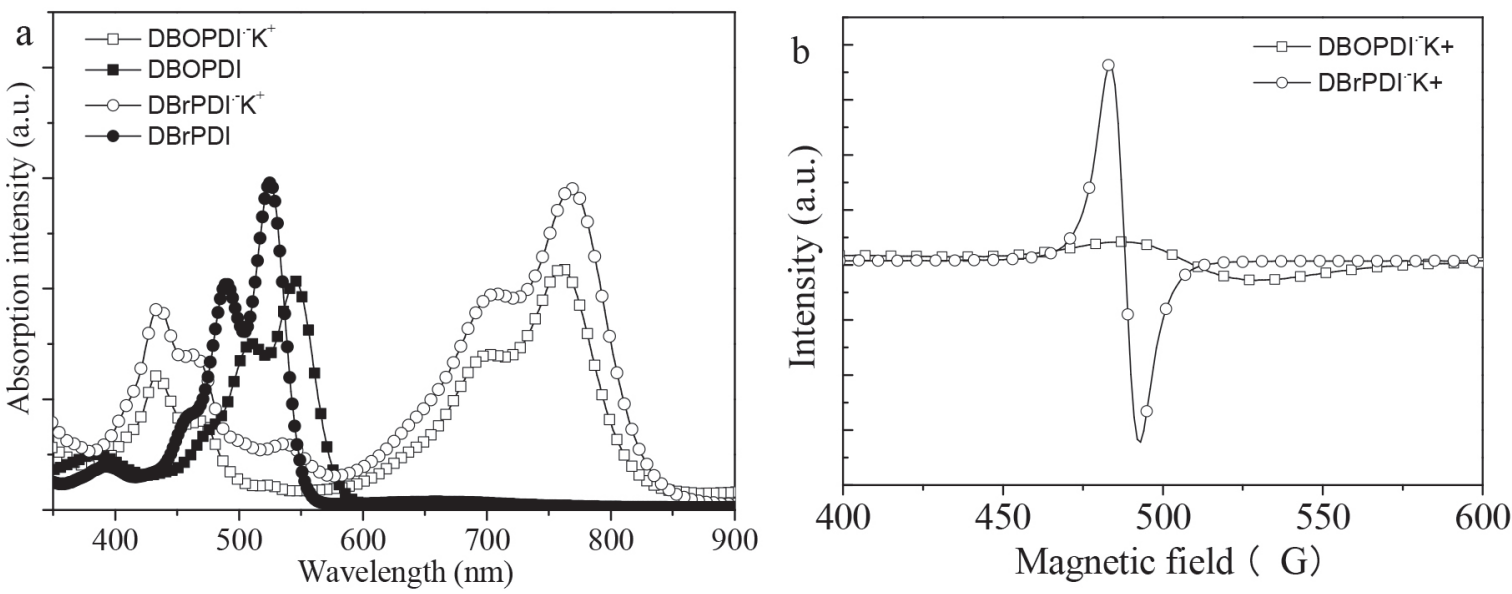

Figure 1. a: UV-vis spectra of DBrPDI, DBrPDI- $k^{+}$, DBOPDI and DBOPDI- $k^{+}$in DMF; $b$ : EPR of DBOPDI- $k^{+}$and DBrPDI- $k^{+}$

\section{Effects of bay-substituents on formation rate of the radical anion}

The relationship between reaction time and yield was monitored by UV-vis spectra in order to investigate the effect of withdrawing or donating groups on the formation rate of perylene diimide radical anion salt (Figure 2a, b, c). Absorption peak at $525 \mathrm{~nm}$ and 545 for DBrPDI and DBOPDI assigned to $0-0$ transition of neutral PDIs. ${ }^{16}$ With increasing reaction time, the UV/Vis-NIR characteristic peaks appeared at around $434 \mathrm{~nm}$ and $760 \mathrm{~nm}$ for bay-substituted PDI
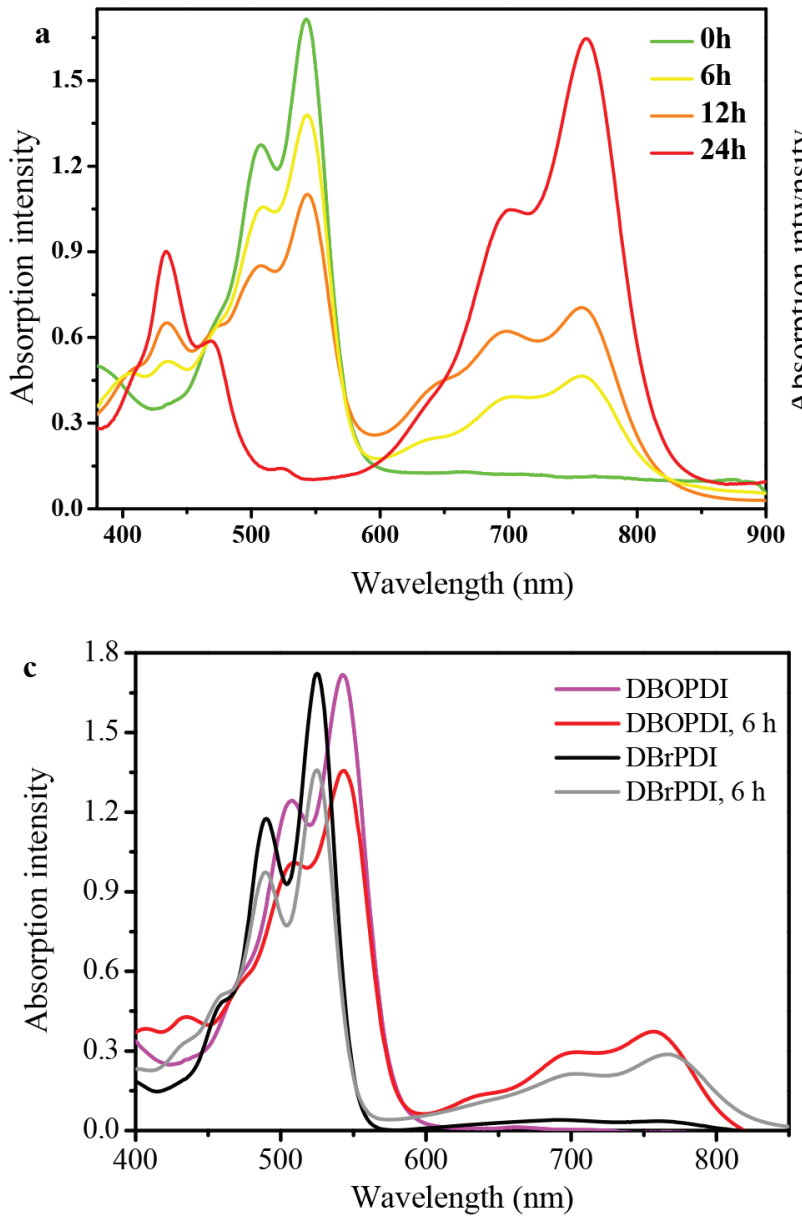

(DBrPDI and DBOPDI) indicating the appearance of the PDIs radical anions. ${ }^{18}$ The ratio of absorption intensity $(\lambda=765 \mathrm{~nm}$ and $\lambda=525 \mathrm{~nm}$ ) is proportional to the yield of radical anion. Clearly, the formation rate of radical anion of DBOPDI is higher than that of DBrPDI (Figure $2 \mathrm{c}$ ) at the same time. The result indicated that the formation rate of PDIs radical anion salt by alkali strongly depend on their chemical structure, that is to say, the introduction of donating groups is conducive to the formation of PDIs radical anion.

To address the reduction activity of the PDIs in DMF, the reduction potentials of PDIs in DMF were compared, as is showed in Figure 2
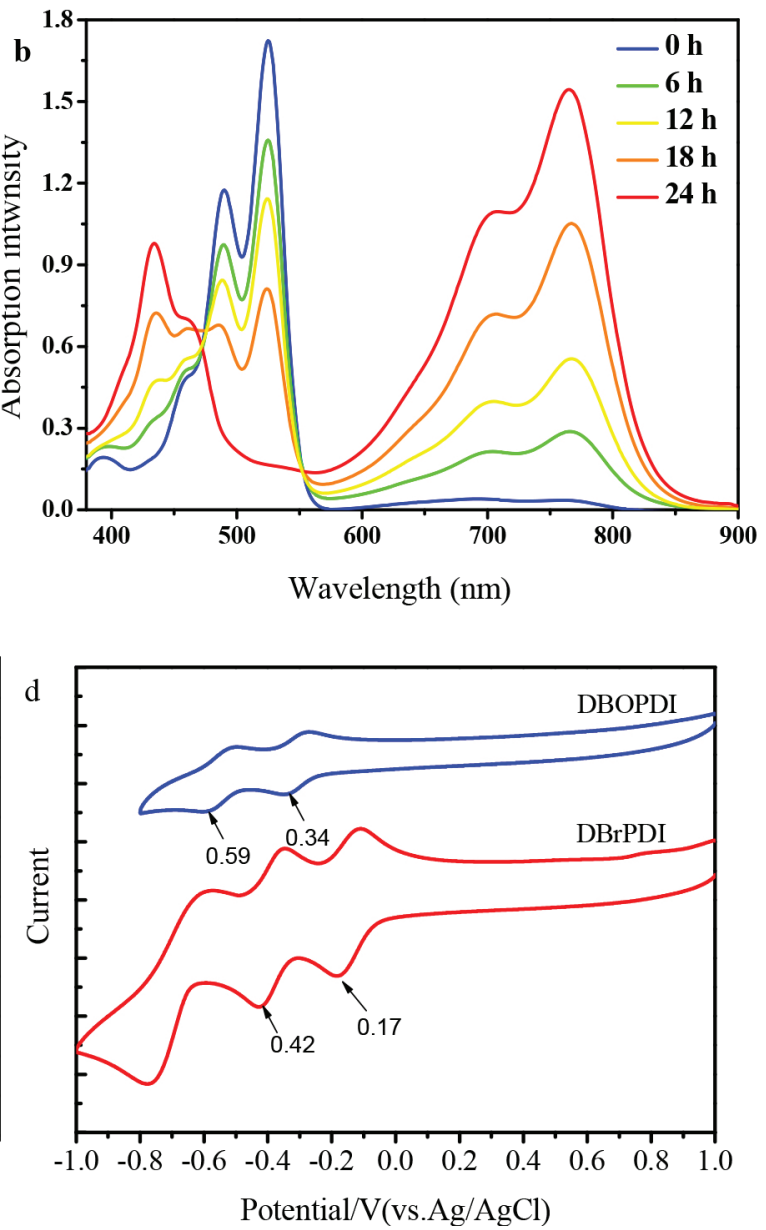

Figure 2. UV-vis spectra of DBOPDI and DBrPDI with the different reaction time in DMF, (a) DBOPDI (b) DBrPDI; (c) A comparison of absorption spectra

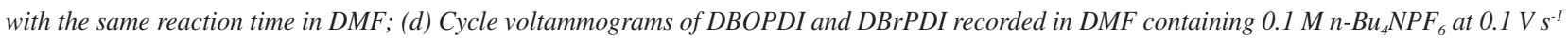


d. PDIs exhibits two reversible reduction waves, which is similar to the typical bay-substituted perylene diimide derivatives. ${ }^{16}$ The first reduction potential for DBOPDI and DBrPDI were $-0.34 \mathrm{~V}$ and -0.17 $\mathrm{V}$, respectively. Thus, the DBrPDI was easier to be reduced to the corresponding radical anion compared to that of DBOPDI. On the contrary, in fact, the formation rate of DBOPDI was larger than that of DBrPDI. This result indicated it is not a simple reduction reaction to prepare to PDIs radical anion salt by leveraging the alkali treatment.

\section{Effects of bay-substituents on UV-vis spectra of PDIs radical anion salt during adding $\mathrm{Cu}^{2+}$}

Our study indicated that the reduced PDI species exhibited the optical response to the different metal ions (such as: $\mathrm{Cu}^{2+}, \mathrm{Hg}^{2+}, \mathrm{Ni}^{2+}$ and $\mathrm{Fe}^{3+}$ ) with different sensitivity. ${ }^{15}$ Similar optical response to the different metal ions also was also observed for DBOPDI- $\mathrm{K}^{+}$and $\mathrm{DBrPDI}^{-} \mathrm{K}^{+}$(Supporting information: Figure $3 \mathrm{~S}$ and $4 \mathrm{~S}$ ). Here, we considered the effect of $\mathrm{Cu}^{2+}$ on $\mathrm{UV}$-vis spectra of two radical anion salt, and the result were shown in Figure 3. Obviously, the intensity of absorption peak of radical anion decreased with titration of the metal ions, while the intensity of absorption peak of neutral PDIs increased. The results indicated that the PDIs radical anion changed into corresponding neutral PDIs after metal ions being added. Furthermore, there was a significant linear correlation between the maximal absorption intensity of radical anion or neutral PDIs and the concentration of metal ions (Figure 4). Therefore, we believe that PDIs radical anion may be advantageous for the detection of heavy metal ions by utilizing the UV-vis spectrophotometer.

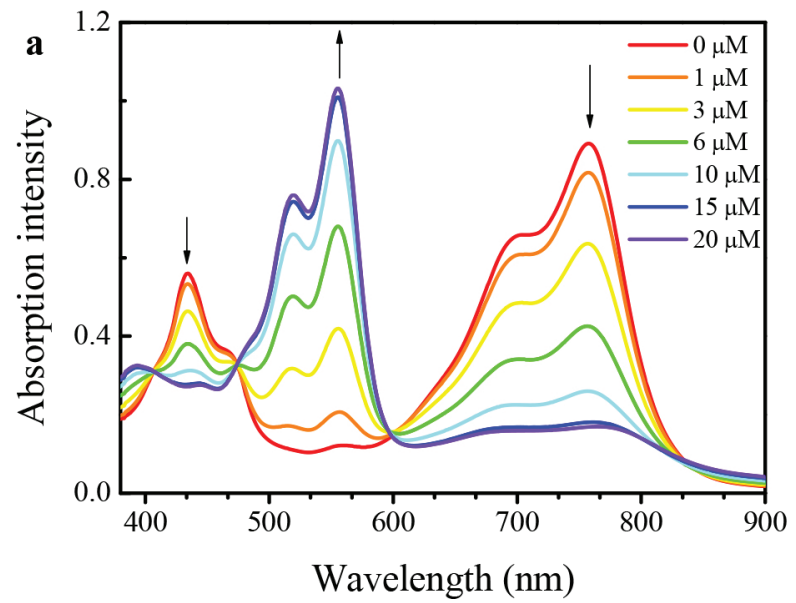

Effects of bay-substituents on selectivity of $\mathrm{Cu}^{2+}$

$\mathrm{Cu}^{2+}$ to the optical sensibility of DBOPDI $\mathrm{k}^{+}$and DBrPDI ${ }^{-} \mathrm{k}^{+}$were discussed by $\left(\mathrm{I}_{\mathrm{f}}-\mathrm{I}_{0}\right) / \mathrm{I}_{0}$ vs concentration of $\mathrm{Cu}^{2+}$ (here: $\mathrm{I}_{0}$ : intensity before adding $\mathrm{Cu}^{2+} ; \mathrm{I}_{\mathrm{f}}$ : intensity after adding $\mathrm{Cu}^{2+} ; 555 \mathrm{~nm}$ ), as is showed in Figure $4 \mathrm{a}$. $\mathrm{Cu}^{2+}$ to optical sensibility of DBOPDI $\mathrm{k}^{+}$was significantly higher than that of DBrPDI ${ }^{-} \mathrm{k}^{+}$. Here, a more likely explanation for this phenomenon is that redox reactions occurred between PDIs radical anion and $\mathrm{Cu}^{2+}$. PDIs radical anion was oxidized to corresponding neutral PDIs and $\mathrm{Cu}^{2+}$ was reduced to $\mathrm{Cu}^{+}$or $\mathrm{Cu}$. The similar reaction has been reported by Screttas CG based on chemical reaction between the magnesium chloride and sodium naphthalene radical anion. ${ }^{19}$ Therefore, $\mathrm{Cu}^{2+}$ to the optical sensibility of DBOPDI ${ }^{*}{ }^{+}$and DBrPDI$\mathrm{k}^{+}$that the reaction rate between PDIs radical anion and $\mathrm{Cu}^{2+}$ depend on the difference between the PDI/PDI- and $\mathrm{Cu}^{2+} / \mathrm{cu}^{+}$or $\mathrm{Cu}^{2+} / \mathrm{cu}^{0}$ (Figure 4b). Clearly, DBOPDI radical anion with $\mathrm{Cu}^{2+}$ has a higher reaction rate compared to that of the DBrPDI radical anion.

\section{CONCLUSIONS}

Two perylene diimide radical salt with different substituents at bay position were synthesized by using the alkali treatment in DMF solution. The formation rate of radical anion salt, and the difference of response to $\mathrm{Cu}^{2+}$, were depend on bay-substituents. The introduction of electron-donating groups at bay-position of perylene diimide [4-(1,1-dimethylethyl)phenoxyl] is favourable to increasing the formation rate of radical anion salt, and the optical sensitive to metal ions.

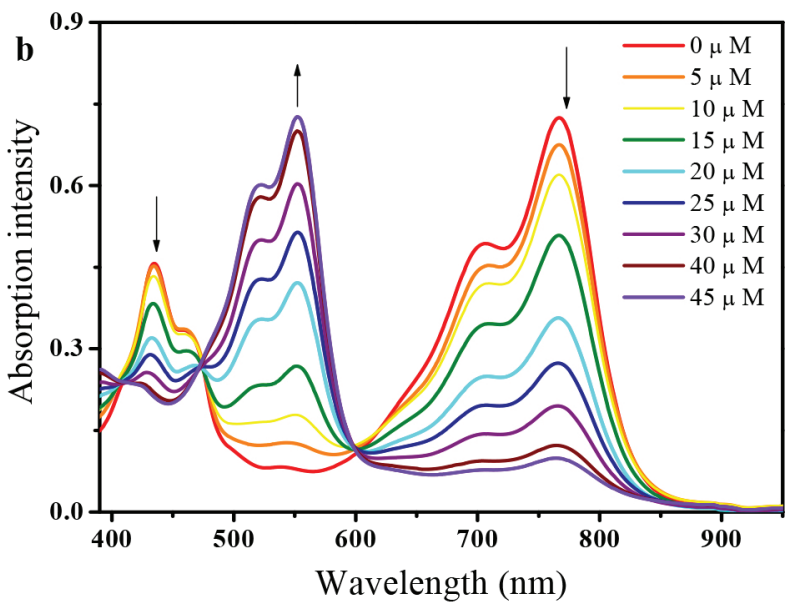

Figure 3. UV-vis spectra titration of PDIs radica anion salt with different concentration of $\mathrm{Cu}^{2+},\left(a: D B O P D I-k^{+} ; b: D B r P D I-k^{+}\right)$

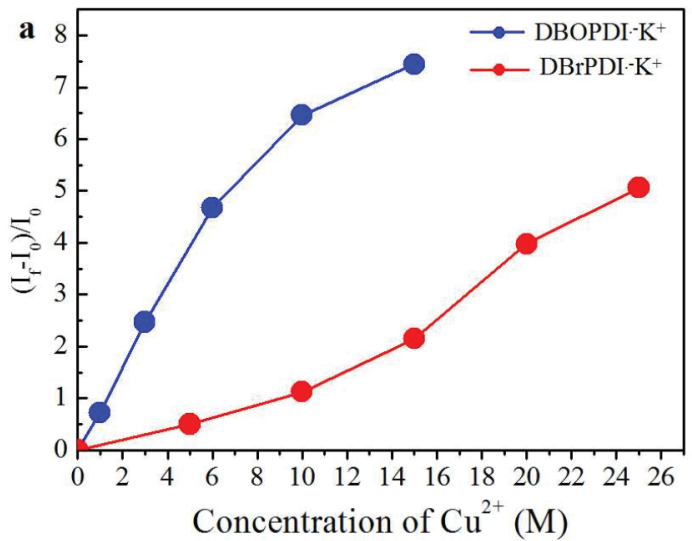

b

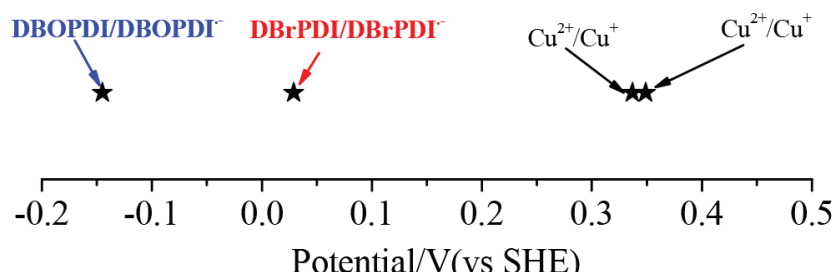

Figure 4. $a:\left(I_{f} I_{0}\right) / I_{0}$ vs concentration of $\mathrm{Cu}^{2+}$ (here: $I_{0}$ : intensity before adding $\mathrm{Cu}^{2+} ; \mathrm{I}_{f}:$ intensity after adding $\left.C u^{2+} ; \lambda=555 \mathrm{~nm}\right)$; $b: \mathrm{DBOPDI} / \mathrm{DBOPDI}$, DBrPDI/DBrPDI, $\mathrm{Cu}^{2+} / \mathrm{Cu}^{+}$and $\mathrm{Cu}^{2+} / \mathrm{Cu}^{0}$ 


\section{SUPPLEMENTARY MATERIAL}

Figures 1S-4S are freely available at http://quimicanova.sbq.org. br, in pdf format.

\section{ACKNOWLEDGEMENTS}

This work was supported by the National Natural Science Foundation of China (No: 51673157, 51472214).

\section{REFERENCES}

1. Nazari, M.; Cieplechowicz, E.; Welsha, T. A.; Welch, G. C.; New J. Chem. 2019, 43, 5187.

2. Chueh, C. H. C. C.; Xi, X. X.; Zhong, H. L.; Gao, G. P.; Wang, Z. H.; Pozzo, L. D.; Wen, T. C.; Jen, A. K. Y.; Adv. Fun. Mater. 2015, 25, 5326.

3. Weng, K. K.; Li, C., Bi, P. Q.; Ryu, H. S.; Guo, Y. K.; Hao, X. T.; Zhao, D. H.; Li, W. W.; Woo, H. Y.; Sun, Y. M.; J. Mater. Chem., A 2019, 7, 3552.

4. Gregg, B. A.; Cormier, R. A.; J. Am. Chem. Soc. 2001, 123, 7959.

5. Wang, J. M.; He, E. F.; Liu, X. Q.; Yu, L.; Wang, H. L.; Zhang, R. J.; Zhang, H. Q.; Sens. Actuators, B 2017, 239, 898.

6. Jiao, Y.; Liu, K.; Wang, G.; Wang, P. Y.; Zhang, X.; Chem. Sci. 2015, 6, 3975.
7. Ghosh, I.; Ghosh, T.; Bardagi, J. I.; König, B.; Science 2014, 346, 725.

8. Zhong, L.; Xing, F. F.; Shi, W.; Yan, L. M.; Xie, L. Q.; Zhu, S. R.; ACS Appl. Mater. Interfaces 2013, 5, 3401.

9. Shirman, E.; Ustinov, A.; Ben-Shitrit, N.; Weissman, H.; Iron, M. A.; Cohen, R.; Rybtchinski, B.; J. Phys. Chem. B 2008, 112, 8855

10. Wang, J. M.; He, E. F.; Wang, H. L.; Hou, W. L.;Xu, J.; Guo, H. Y.; Wang, X.; Zhang, Z. L.; Zhang, R. J.; Zhang, H. Q.; RSC Adv. 2016, 6, 68402 .

11. Gosztola, D.; Niemczyk, M. P.; Svec, W.; Lukas, A. S.; Wasielewski, M. R.; J. Phys. Chem. A 2000, 104, 6545.

12. Marcon, R. O.; Brochsztain, S.; Langmuir, 2007, 23, 11972.

13. Roznyatovskiy, V. V.; Gardner, D. M.; Eaton, S.W.; Wasielewski, M. R.; Org. Lett. 2014, 16, 696.

14. Seifert, S.; Schmidt, D.; Würthner, F.; Chem. Sci. 2015, 6, 1663.

15. He, E. F.; Wang, J. M.; Xu, H.; He, Z. M.; Wang, H. L.; Zhao, H.; Zhang, Y. Y.; Zhang, R. J.; Zhang, H. Q.; J. Mater. Sci. 2016, 14, 6583.

16. Zhao, H.; Zhang, Y. Y.; Xu, H.; He, Z. M.; Zhang, Z. L.; Zhang, H. Q.; Tetrahedron 2005, 71, 7752.

17. Marcon, R. O.; Brochsztain, S.; J. Phys. Chem. A 2009, 113, 1747.

18. Lu, W.; Gao, J. P.; Wang, Z. Y.; Qi, Y.; Sacripante, G. G.; Duff, J. D.; Sundararajan, P. R.; Macromolecules 1999, 32, 8880.

19. Steele, B. R.; Heropoulos, G. A.; Screttas, C. G.; Collect. Czech. Chem. Commun. 2007, 72, 589. 